\title{
Coupled $g$-coincidence point theorems for a generalized compatible pair in complete metric spaces
}

\author{
Narawadee Na Nan* and Phakdi Charoensawan
}

\author{
*Correspondence: \\ narawadee_n@hotmail.co.th \\ Department of Mathematics, \\ Faculty of Science, Chiang Mai \\ University, Chiang Mai, 50200, \\ Thailand
}

\begin{abstract}
In this work, we give the notions of coupled $g$-coincidence point and $H_{g}$-increasing property of $F$ for mappings $F, H: X \times X \rightarrow X$ and $g: X \rightarrow X$ and prove the existence and uniqueness of a coupled $g$-coincidence point theorem for mappings $F, H: X \times X \rightarrow X$ and $g: X \rightarrow X$ with $\varphi$-contraction mappings in complete metric spaces without the $H_{g}$-increasing property of $F$ and the mixed monotone property of $G$. Further, we apply our results to the existence and uniqueness of a coupled $g$-coincidence point of the given mappings with the $\mathrm{H}_{\mathrm{g}}$-increasing property of $\mathrm{F}$ and the mixed monotone property of $H$ in partially ordered metric spaces.

Keywords: coupled fixed point; coupled coincidence point; coupled g-coincidence point; $H_{g}$-increasing; generalized compatible; invariant set; closed set; mixed g-monotone; partially ordered set
\end{abstract}

\section{Introduction}

In 2004, the study of a fixed point in partially ordered metric spaces was initiated by Ran and Reurings [1], and continued by Nieto and Lopez [2, 3]. Agarwal et al. [4] and many other authors presented some new results for contractions in partially ordered metric spaces.

In 1987, Guo and Lakshmikantham [5] introduced the concept of coupled fixed point. Afterwards, Bhaskar and Lakshmikantham [6] introduced the concept of mixed monotone property for contractive operators in partially ordered metric spaces and proved coupled fixed point theorems for mappings which satisfy the mixed monotone property. They also gave some applications on the existence and uniqueness of the coupled fixed point theorems for such mappings. As a continuation of this trend, Lakshimikantham and Ćirić [7] extended the results in [6] by defining the mixed $g$-monotonicity and studied the existence and uniqueness of a coupled coincidence point for such mappings which satisfy the mixed monotone property in partially ordered metric spaces. For more work on the coupled fixed point theory and coupled coincidence point theory in partially ordered metric spaces and different spaces, we refer to the reviews (see, e.g., [8-48]).

One of the interesting ways to develop coupled fixed point theory in partially ordered metric spaces is to consider the mapping $F: X \times X \rightarrow X$ without the mixed monotone property. In 2012, Sintunavarat et al. [44, 45] proved some coupled fixed point theorems

○2014 Na Nan and Charoensawan; licensee Springer. This is an Open Access article distributed under the terms of the Creative Commons Attribution License (http://creativecommons.org/licenses/by/2.0), which permits unrestricted use, distribution, and reproduction in any medium, provided the original work is properly cited. 
for nonlinear contractions without the mixed monotone property and extended some coupled fixed point theorems of Bhaskar and Lakshmikantham [6] by using the concept of F-invariant set due to Samet and Vetro [49]. Later, Charoensawan and Klanarong [22] proved the existence and uniqueness of a coupled coincidence point in partially ordered metric spaces without the mixed $g$-monotone property of $F: X \times X \rightarrow X$ and $g: X \rightarrow X$. Recently, Kutbi et al. [48] introduced the concept of $F$-closed set which is weaker than the concept of $F$-invariant set and proved some coupled fixed point theorems without the condition of mixed monotone property. Following this trend, many authors have studied fixed point theorems for nonlinear contractions without the monotone property in several spaces (see, e.g., $[14,50-56])$.

Very recently, Hussain et al. [47] presented the new concept of generalized compatibility of a pair $\{F, G\}$ of mappings $F, G: X \times X \rightarrow X$ and proved some coupled coincidence point results of such mappings without the mixed $G$-monotone property of $F$, which generalized some recent comparable results in the literature. They also gave some examples and an application to integral equations to support the result.

In this work, we give the notion of coupled $g$-coincidence point and the $H_{g}$-increasing property of $F$ for mappings $F, H: X \times X \rightarrow X$ and $g: X \rightarrow X$. We apply our results to the existence and uniqueness of a coupled $g$-coincidence point of the given mapping with the $H_{g}$-increasing property of $F$ and the mixed monotone property of $H$ in partially ordered metric spaces which generalize and extend the coupled coincidence point theorem in [47].

\section{Preliminaries}

In this section, we give some definitions, propositions, examples, and remarks which are useful for the main results in this paper. Throughout this paper, $(X, \preceq)$ denotes a partially ordered set with the partial order $\preceq$. By $x \preceq y$, we mean $y \succeq x$. Let $(x, \preceq)$ be a partially ordered set, the partial order $\preceq_{2}$ for the product set $X \times X$ defined in the following way: for all $(x, y),(u, v) \in X \times X$,

$$
(x, y) \preceq_{2}(u, v) \quad \Rightarrow \quad H(x, y) \preceq H(u, v) \quad \text { and } \quad H(v, u) \preceq H(y, x)
$$

where $H: X \times X \rightarrow X$ is one-one.

We say that $(x, y)$ is comparable to $(u, v)$ if either $(x, y) \preceq_{2}(u, v)$ or $(u, v) \preceq_{2}(x, y)$.

Guo and Lakshmikantham [5] introduced the concept of coupled fixed point as follows.

Definition 2.1 [5] An element $(x, y) \in X \times X$ is called a coupled fixed point of a mapping $F: X \times X \rightarrow X$ if $F(x, y)=x$ and $F(y, x)=y$.

The concept of mixed monotone property was introduced by Bhaskar and Lakshmikantham in [6].

Definition 2.2 [6] Let $(X, \preceq)$ be a partially ordered set and $F: X \times X \rightarrow X$. We say that $F$ has the mixed monotone property if for any $x, y \in X$,

$$
x_{1}, x_{2} \in X, \quad x_{1} \preceq x_{2} \quad \text { implies } \quad F\left(x_{1}, y\right) \preceq F\left(x_{2}, y\right)
$$

and

$$
y_{1}, y_{2} \in X, \quad y_{1} \preceq y_{2} \quad \text { implies } \quad F\left(x, y_{1}\right) \succeq F\left(x, y_{2}\right) .
$$


Lakshmikantham and Ćirić in [7] introduced the concepts of mixed $g$-monotone mapping and coupled coincidence point.

Definition 2.3 [7] Let $(X, \preceq)$ be a partially ordered set and $F: X \times X \rightarrow X$ and $g: X \rightarrow X$. We say that $F$ has the mixed $g$-monotone property if for any $x, y \in X$,

$$
x_{1}, x_{2} \in X, \quad g x_{1} \preceq g x_{2} \quad \text { implies } \quad F\left(x_{1}, y\right) \preceq F\left(x_{2}, y\right)
$$

and

$$
y_{1}, y_{2} \in X, \quad g y_{1} \preceq g y_{2} \quad \text { implies } \quad F\left(x, y_{1}\right) \succeq F\left(x, y_{2}\right) .
$$

Definition 2.4 [7] An element $(x, y) \in X \times X$ is called a coupled coincidence point of mappings $F: X \times X \rightarrow X$ and $g: X \rightarrow X$ if $F(x, y)=g x$ and $F(y, x)=g y$.

Definition 2.5 [7] Let $X$ be a non-empty set and $F: X \times X \rightarrow X$ and $g: X \rightarrow X$. We say that $F$ and $g$ are commutative if $g F(x, y)=F(g x, g y)$ for all $x, y \in X$.

Hussain et al. [47] introduced the concept of $G$-increasing and $\{F, G\}$ generalized compatibility as follows.

Definition 2.6 [47] Suppose that $F, G: X \times X \rightarrow X$ are two mappings. $F$ is said to be $G$ increasing with respect to $\preceq$ if for all $x, y, u, v \in X$, with $G(x, y) \preceq G(u, v)$, we have $F(x, y) \preceq$ $F(u, v)$.

Definition 2.7 [47] An element $(x, y) \in X \times X$ is called a coupled coincidence point of mappings $F, G: X \times X \rightarrow X$ if $F(x, y)=G(x, y)$ and $F(y, x)=G(y, x)$.

Definition 2.8 [47] Let $F, G: X \times X \rightarrow X$. We say that the pair $\{F, G\}$ is generalized compatible if

$$
\begin{cases}d\left(F\left(G\left(x_{n}, y_{n}\right), G\left(y_{n}, x_{n}\right)\right), G\left(F\left(x_{n}, y_{n}\right), F\left(y_{n}, x_{n}\right)\right)\right) \rightarrow 0 & \text { as } n \rightarrow+\infty \\ d\left(F\left(G\left(y_{n}, x_{n}\right), G\left(x_{n}, y_{n}\right)\right), G\left(F\left(y_{n}, x_{n}\right), F\left(x_{n}, y_{n}\right)\right)\right) \rightarrow 0 & \text { as } n \rightarrow+\infty\end{cases}
$$

whenever $\left(x_{n}\right)$ and $\left(y_{n}\right)$ are sequences in $X$ such that

$$
\left\{\begin{array}{l}
\lim _{n \rightarrow \infty} F\left(x_{n}, y_{n}\right)=\lim _{n \rightarrow \infty} G\left(x_{n}, y_{n}\right)=t_{1}, \\
\lim _{n \rightarrow \infty} F\left(y_{n}, x_{n}\right)=\lim _{n \rightarrow \infty} G\left(y_{n}, x_{n}\right)=t_{2} .
\end{array}\right.
$$

Definition 2.9 [47] Let $F, G: X \times X \rightarrow X$ be two maps. We say that the pair $\{F, G\}$ is commuting if

$$
F(G(x, y), G(y, x))=G(F(x, y), F(y, x)) \quad \text { for all } x, y \in X .
$$

Let $\Theta$ denote the set of all functions $\phi:[0, \infty) \rightarrow[0, \infty)$ such that:

(i) $\phi$ is continuous and increasing, 
(ii) $\phi(t)=0$ if and only if $t=0$,

(iii) $\phi(t+s) \leq \phi(t)+\phi(s)$ for all $t, s \in[0, \infty)$.

Let $\Psi$ be the set of all functions $\psi:[0, \infty) \rightarrow[0, \infty)$ such that $\lim _{t \rightarrow r} \psi(t)>0$ for all $r>0$ and $\lim _{t \rightarrow 0^{+}} \psi(t)=0$.

Hussain et al. [47] proved the coupled coincidence point for such mappings involving the $(\psi, \phi)$-contractive condition as follows.

Theorem 2.10 [47] Let $(X, \preceq)$ be a partially ordered set and $M$ be a non-empty subset of $X^{4}$, and let $d$ be a metric on $X$ such that $(X, d)$ is a complete metric space. Assume that $F, G: X \times X \rightarrow X$ are two generalized compatible mappings such that $F$ is G-increasing with respect to $\preceq, G$ is continuous and has the mixed monotone property. Suppose that for any $x, y \in X$, there exist $u, v \in X$ such that $F(x, y)=G(u, v)$ and $F(y, x)=G(v, u)$. Suppose that there exist $\phi \in \Theta$ and $\psi \in \Psi$ such that the following holds:

$$
\begin{aligned}
\phi(d(F(x, y), F(u, v))) \leq & \frac{1}{2} \phi(d(G(x, y), G(u, v))+d(G(y, x), G(v, u))) \\
& -\psi\left(\frac{d(G(x, y), G(u, v))+d(G(y, x), G(v, u))}{2}\right)
\end{aligned}
$$

for all $x, y, u, v \in X$ with $G(x, y) \preceq G(u, v)$ and $G(y, x) \succeq G(v, u)$.

Also suppose that either

(a) $F$ is continuous, or

(b) $X$ has the following properties: for any two sequences $\left\{x_{n}\right\}$ and $\left\{y_{n}\right\}$

(i) if a non-decreasing sequence $\left\{x_{n}\right\} \rightarrow x$, then $x_{n} \preceq x$ for all $n$,

(ii) if a non-increasing sequence $\left\{y_{n}\right\} \rightarrow y$, then $y \preceq y_{n}$ for all $n$.

If there exists $\left(x_{0}, y_{0}\right) \in X \times X$ with

$$
G\left(x_{0}, y_{0}\right) \preceq F\left(x_{0}, y_{0}\right) \quad \text { and } \quad G\left(y_{0}, x_{0}\right) \succeq F\left(y_{0}, x_{0}\right) \text {, }
$$

then there exists $(x, y) \in X \times X$ such that $G(x, y)=F(x, y)$ and $G(y, x)=F(y, x)$, that is, $F$ and $G$ have a coupled coincidence point.

Kutbi et al. [48] introduced the notion of $F$-closed set which extended the notion of $F$-invariant set as follows.

Definition 2.11 [48] Let $F: X \times X \rightarrow X$ be a mapping, and let $M$ be a subset of $X^{4}$. We say that $M$ is an $F$-closed subset of $X^{4}$ if, for all $x, y, u, v \in X$,

$$
(x, y, u, v) \in M \quad \Rightarrow \quad(F(x, y), F(y, x), F(u, v), F(v, u)) \in M
$$

Now, we give the notion of a coupled $g$-coincidence point and a $\left(H_{g}, F\right)$-closed set which is useful for our main results.

Definition 2.12 Suppose that $F, H: X \times X \rightarrow X$ are two mappings and $g: X \rightarrow X$. $F$ is said to be $H_{g}$-increasing with respect to $\preceq$ if for all $x, y, u, v \in X$, with $H(g x, g y) \preceq H(g u, g v)$, we have $F(x, y) \preceq F(u, v)$. 
Example 2.13 Let $X=N$ endowed with the natural ordering of real number $\leq$. Define the mappings $F, H: X \times X \rightarrow X$ and $g: X \rightarrow X$ by $F(x, y)=(x+y)^{2}, H(x, y)=x+y$ and $g x=x / 2$ for all $x, y \in X$. Note that $F$ is $H_{g}$-increasing with respect to $\leq$.

Example 2.14 Let $X=\mathbb{R}$ endowed with the natural ordering of real number $\leq$. Define the mappings $F, H: X \times X \rightarrow X$ and $g: X \rightarrow X$ by $F(x, y)=2+y-x, H(x, y)=x-y$ and $g x=1-x$ for all $x, y \in X$. Note that $F$ is $H_{g}$-increasing with respect to $\leq$ but not $H$-increasing. If $H(x, y)=x-y \leq H(u, v)=u-v$, then $F(x, y)=2+y-x \geq F(u, v)=2+v-u$, but if $H(g x, g y)=$ $y-x \leq H(g u, g v)=v-u$, then $F(x, y)=2+y-x \leq F(u, v)=2+v-u$.

Definition 2.15 An element $(x, y) \in X \times X$ is called a coupled $g$-coincidence point of mappings $F, H: X \times X \rightarrow X$ and $g: X \rightarrow X$ if $F(x, y)=H(g x, g y)$ and $F(y, x)=H(g y, g x)$.

Example 2.16 Let $X=\mathbb{R}$ endowed with the natural ordering of real number $\leq$. Define the mappings $F, H: X \times X \rightarrow X$ and $g: X \rightarrow X$ by $F(x, y)=x^{2}+\frac{3 y^{2}}{2}, H(x, y)=x+y$ and $g x=\frac{x}{2}$ for all $x, y \in X$. Note that $(0,0)$ is a coupled $g$-coincidence point.

Definition 2.17 Let $(X, d)$ be a metric space and $F, H: X \times X \rightarrow X$ be two mappings and $g: X \rightarrow X$. Let $M$ be a subset of $X^{4}$. We say that $M$ is an $\left(H_{g}, F\right)$-closed subset of $X^{4}$ if for all $x, y, u, v \in X$,

$$
\begin{gathered}
(H(g x, g y), H(g y, g x), H(g u, g v), H(g v, g u)) \in M \\
\Rightarrow \quad(F(x, y), F(y, x), F(u, v), F(v, u)) \in M .
\end{gathered}
$$

Definition 2.18 Let $(X, d)$ be a metric space and $H: X \times X \rightarrow X$ be a given mapping. Let $M$ be a subset of $X^{4}$. We say that $M$ satisfies the transitive property if and only if, for all $x, y, u, v, a, b \in X$,

$$
\begin{aligned}
& (H(x, y), H(y, x), H(u, v), H(v, u)) \in M \quad \text { and } \\
& (H(u, v), H(v, u), H(a, b), H(b, a)) \in M \\
& \quad \Rightarrow \quad(H(x, y), H(y, x), H(a, b), H(b, a)) \in M .
\end{aligned}
$$

Remark The set $M=X^{4}$ is a trivially $\left(H_{g}, F\right)$-closed set, which satisfies the transitive property.

Example 2.19 Let $X=\{0,1,2,3\}$ endowed with the usual metric and $F, H: X \times X \rightarrow X$ be defined by

$$
F(x, y)= \begin{cases}1, & x, y \in\{1,2\}, \\ 3, & \text { otherwise }\end{cases}
$$

and

$$
H(x, y)= \begin{cases}1, & x, y \in\{0,1\} \\ 3, & \text { otherwise }\end{cases}
$$


Let $g: X \rightarrow X$ be defined by

$$
g(x)= \begin{cases}1, & x \in\{1,2\} \\ 3, & \text { otherwise }\end{cases}
$$

It is easy to see that $M=\{0,1\}^{4} \subset X^{4}$ is an $\left(H_{g}, F\right)$-closed set but not an $F$-closed set.

Definition 2.20 Let $F, H: X \times X \rightarrow X$ and $g: X \rightarrow X$. We say that the pair $\{F, H\}$ is $g$-generalized compatible if

$$
\left\{\begin{array}{l}
d\left(F\left(H\left(g x_{n}, g y_{n}\right), H\left(g y_{n}, g x_{n}\right)\right), H\left(g F\left(x_{n}, y_{n}\right), g F\left(y_{n}, x_{n}\right)\right)\right) \rightarrow 0 \text { as } n \rightarrow+\infty \\
d\left(F\left(H\left(g y_{n}, g x_{n}\right), H\left(g x_{n}, g y_{n}\right)\right), H\left(g F\left(y_{n}, x_{n}\right), g F\left(x_{n}, y_{n}\right)\right)\right) \rightarrow 0 \text { as } n \rightarrow+\infty
\end{array}\right.
$$

whenever $\left(x_{n}\right),\left(g x_{n}\right),\left(y_{n}\right)$, and $\left(g y_{n}\right)$ are sequences in $X$ such that

$$
\left\{\begin{array}{l}
\lim _{n \rightarrow \infty} F\left(x_{n}, y_{n}\right)=\lim _{n \rightarrow \infty} H\left(g x_{n}, g y_{n}\right)=t_{1}, \\
\lim _{n \rightarrow \infty} F\left(y_{n}, x_{n}\right)=\lim _{n \rightarrow \infty} H\left(g y_{n}, g x_{n}\right)=t_{2} .
\end{array}\right.
$$

Example 2.21 Let $(X, d)$ be a metric space endowed with a partial order $\preceq$. Let $g: X \rightarrow X$ and $F, H: X \times X \rightarrow X$ be two mappings such that $F$ is $H_{g}$-increasing with respect to $\preceq$. Define a subset $M \subseteq X^{4}$ by

$$
M=\left\{(x, y, u, v) \in X^{4}: x \preceq u, y \succeq v\right\} .
$$

Let $(H(g x, g y), H(g y, g x), H(g u, g v), H(g v, g u)) \in M$. Since $F$ is $H_{g}$-increasing with respect to $\preceq$, we have $F(x, y) \preceq F(u, v)$ and $F(y, x) \succeq F(v, u)$, and this implies that $(F(x, y), F(y, x)$, $F(u, v), F(v, u)) \in M$. Then $M$ is an $\left(H_{g}, F\right)$-closed subset of $X^{4}$ which satisfies the transitive property.

\section{Main results}

Let $\Phi$ denote the set of functions $\varphi:[0, \infty) \rightarrow[0, \infty)$ satisfying

1. $\varphi(t)<t$ for all $t>0$,

2. $\lim _{r \rightarrow t^{+}} \varphi(r)<t$ for all $t>0$.

Now, we state our first main theorem which guarantees a coupled $g$-coincidence point.

Theorem 3.1 Let $(X, d)$ be a complete metric space and $M$ be a non-empty subset of $X^{4}$. Assume that $g: X \rightarrow X$ is continuous and $F, H: X \times X \rightarrow X$ are two generalized compatible mappings such that $H$ is continuous, and for any $x, y \in X$, there exist $u, v \in X$ such that $F(x, y)=H(g u, g v)$ and $F(y, x)=H(g v, g u)$. Suppose that there exists $\varphi \in \Phi$ such that the following holds:

$$
\begin{aligned}
& d(F(x, y), F(u, v))+d(F(y, x), F(v, u)) \\
& \quad \leq \varphi(d(H(g x, g y), H(g u, g v))+d(H(g y, g x), H(g v, g u)))
\end{aligned}
$$

for all $x, y, u, v \in X$ with $(H(g x, g y), H(g y, g x), H(g u, g v), H(g v, g u)) \in M$. 
Also suppose that $F$ is continuous. If there exists $\left(x_{0}, y_{0}\right) \in X$ such that

$$
\left(H\left(g x_{0}, g y_{0}\right), H\left(g y_{0}, g x_{0}\right), F\left(x_{0}, y_{0}\right), F\left(y_{0}, x_{0}\right)\right) \in M
$$

and $M$ is $\left(H_{g}, F\right)$-closed, then there exists $(x, y) \in X \times X$ such that $H(g x, g y)=F(x, y)$ and $H(g y, g x)=F(y, x)$, that is, $F$ and $H$ have a coupled $g$-coincidence point.

Proof Let $x_{0}, y_{0} \in X$ be such that

$$
\left(H\left(g x_{0}, g y_{0}\right), H\left(g y_{0}, g x_{0}\right), F\left(x_{0}, y_{0}\right), F\left(y_{0}, x_{0}\right)\right) \in M \text {. }
$$

From the assumption, there exist $\left(x_{1}, y_{1}\right) \in X \times X$ such that

$$
F\left(x_{0}, y_{0}\right)=H\left(g x_{1}, g y_{1}\right) \quad \text { and } \quad F\left(y_{0}, x_{0}\right)=H\left(g y_{1}, g x_{1}\right) .
$$

Again from assumption, we can choose $x_{2}, y_{2} \in X$ such that

$$
F\left(x_{1}, y_{1}\right)=H\left(g x_{2}, g y_{2}\right) \quad \text { and } \quad F\left(y_{1}, x_{1}\right)=H\left(g y_{2}, g x_{2}\right) .
$$

By repeating this argument, we can construct sequences such that for all $n \geq 1$,

$$
F\left(x_{n}, y_{n}\right)=H\left(g x_{n+1}, g y_{n+1}\right) \quad \text { and } \quad F\left(y_{n}, x_{n}\right)=H\left(g y_{n+1}, g x_{n+1}\right) .
$$

Since $\left(H\left(g x_{0}, g y_{0}\right), H\left(g y_{0}, g x_{0}\right), F\left(x_{0}, y_{0}\right), F\left(y_{0}, x_{0}\right)\right) \in M$ and $M$ is $\left(H_{g}, F\right)$-closed, we get

$$
\begin{aligned}
& \left(H\left(g x_{0}, g y_{0}\right), H\left(g y_{0}, g x_{0}\right), F\left(x_{0}, y_{0}\right), F\left(y_{0}, x_{0}\right)\right) \\
& =\left(H\left(g x_{0}, g y_{0}\right), H\left(g y_{0}, g x_{0}\right), H\left(g x_{1}, g y_{1}\right), H\left(g y_{1}, g x_{1}\right)\right) \in M \\
& \Rightarrow \quad\left(F\left(x_{0}, y_{0}\right), F\left(y_{0}, x_{0}\right), F\left(x_{1}, y_{1}\right), F\left(y_{1}, x_{1}\right)\right) \\
& \quad=\left(H\left(g x_{1}, g y_{1}\right), H\left(g y_{1}, g x_{1}\right), H\left(g x_{2}, g y_{2}\right), H\left(g y_{2}, g x_{2}\right)\right) \in M .
\end{aligned}
$$

Again, using the fact that $M$ is $\left(H_{g}, F\right)$-closed, we have

$$
\begin{aligned}
& \left(H\left(g x_{1}, g y_{1}\right), H\left(g y_{1}, g x_{1}\right), H\left(g x_{2}, g y_{2}\right), H\left(g y_{2}, g x_{2}\right)\right) \in M \\
& \Rightarrow \quad\left(F\left(x_{2}, y_{2}\right), F\left(y_{2}, x_{2}\right), F\left(x_{3}, y_{3}\right), F\left(y_{3}, x_{3}\right)\right) \\
& \quad=\left(H\left(g x_{2}, g y_{2}\right), H\left(g y_{2}, g x_{2}\right), H\left(g x_{3}, g y_{3}\right), H\left(g y_{3}, g x_{3}\right)\right) \in M .
\end{aligned}
$$

Continuing this process, for all $n \geq 0$, we get

$$
\left(H\left(g x_{n}, g y_{n}\right), H\left(g y_{n}, g x_{n}\right), H\left(g x_{n+1}, g y_{n+1}\right), H\left(g y_{n+1}, g x_{n+1}\right)\right) \in M
$$

For all $n \geq 0$, denote

$$
\delta_{n}:=d\left(H\left(g x_{n}, g y_{n}\right), H\left(g x_{n+1}, g y_{n+1}\right)\right)+d\left(H\left(g y_{n}, g x_{n}\right), H\left(g y_{n+1}, g x_{n+1}\right)\right) .
$$


We can suppose that $\delta_{n}>0$ for all $n \geq 0$. If not, $\left(x_{n}, y_{n}\right)$ will be a coupled $g$-coincidence point and the proof is finished. From (1), (2) and (3), we have

$$
\begin{aligned}
& d\left(H\left(g x_{n+1}, g y_{n+1}\right), H\left(g x_{n+2}, g y_{n+2}\right)\right)+d\left(H\left(g y_{n+1}, g x_{n+1}\right), H\left(g y_{n+2}, g x_{n+2}\right)\right) \\
& \quad=d\left(F\left(x_{n}, y_{n}\right), F\left(x_{n+1}, y_{n+1}\right)\right)+d\left(F\left(y_{n}, x_{n}\right), F\left(y_{n+1}, x_{n+1}\right)\right) \\
& \quad \leq \varphi\left(d\left(H\left(g x_{n}, g y_{n}\right), H\left(g x_{n+1}, g y_{n+1}\right)\right)+d\left(H\left(g y_{n}, g x_{n}\right), H\left(g y_{n+1}, g x_{n+1}\right)\right)\right) \\
& \quad=\varphi\left(\delta_{n}\right) .
\end{aligned}
$$

Therefore, the sequence $\left\{\delta_{n}\right\}_{n=1}^{\infty}$ satisfies

$$
\delta_{n+1} \leq \varphi\left(\delta_{n}\right) \text { for all } n \geq 0 .
$$

Using the property of $\varphi$, it follows that the sequence $\left\{\delta_{n}\right\}_{n=1}^{\infty}$ is decreasing. Therefore, there exists some $\delta \geq 0$ such that

$$
\lim _{n \rightarrow \infty} \delta_{n}=\delta
$$

We shall prove that $\delta=0$. Assume, to the contrary, that $\delta>0$. Then by letting $n \rightarrow \infty$ in (6) and using the property of $\varphi$, we have

$$
\delta=\lim _{n \rightarrow \infty} \delta_{n+1} \leq \lim _{n \rightarrow \infty} \varphi\left(\delta_{n}\right)=\lim _{\delta_{n} \rightarrow \delta^{+}} \varphi\left(\delta_{n}\right)<\delta,
$$

a contradiction. Thus $\delta=0$ and hence

$$
\lim _{n \rightarrow \infty} \delta_{n}=0
$$

We now prove that $\left\{H\left(g x_{n}, g y_{n}\right)\right\}_{n=1}^{\infty}$ and $\left\{H\left(g y_{n}, g x_{n}\right)\right\}_{n=1}^{\infty}$ are Cauchy sequences in $(X, d)$. Suppose, to the contrary, that at least one of the sequences $\left\{H\left(g x_{n}, g y_{n}\right)\right\}_{n=1}^{\infty}$ or $\left\{H\left(g y_{n}\right.\right.$, $\left.\left.g x_{n}\right)\right\}_{n=1}^{\infty}$ is not a Cauchy sequence. Then there exists $\epsilon>0$ for which we can find subsequences $\left\{H\left(g x_{m(k)}, g y_{m(k)}\right)\right\},\left\{H\left(g x_{n(k)}, g y_{n(k)}\right)\right\}$ of $\left\{H\left(g x_{n}, g y_{n}\right)\right\}_{n=1}^{\infty}$ and $\left\{H\left(g y_{m(k)}, g x_{m(k)}\right)\right\}$, $\left\{H\left(g y_{n(k)}, g x_{n(k)}\right)\right\}$ of $\left\{H\left(g y_{n}, g x_{n}\right)\right\}_{n=1}^{\infty}$, respectively, with $n(k)>m(k) \geq k$ such that

$$
\begin{aligned}
D_{k}:= & d\left(H\left(g x_{m(k)}, g y_{m(k)}\right), H\left(g x_{n(k)}, g y_{n(k)}\right)\right) \\
& +d\left(H\left(g y_{m(k)}, g x_{m(k)}\right), H\left(g y_{n(k)}, g x_{n(k)}\right)\right) \\
> & \epsilon .
\end{aligned}
$$

Further, corresponding to $m(k)$, we can choose $n(k)$ in such a way that it is the smallest integer with $n(k)>m(k) \geq k$ satisfying $(9)$. Then

$$
\begin{aligned}
d( & \left.H\left(g x_{m(k)}, g y_{m(k)}\right), H\left(g x_{n(k)-1}, g y_{n(k)-1}\right)\right) \\
& +d\left(H\left(y_{m(k)}, x_{m(k)}\right), H\left(g y_{n(k)-1}, g x_{n(k)-1}\right)\right) \\
\leq & \epsilon .
\end{aligned}
$$


Using (9), (10), and the triangle inequality, we have

$$
\begin{aligned}
\epsilon< & D_{k} \\
\leq & d\left(H\left(g x_{m(k)}, g y_{m(k)}\right), H\left(g x_{n(k)-1}, g y_{n(k)-1}\right)\right) \\
& +d\left(H\left(g x_{n(k)-1}, g y_{n(k)-1}\right), H\left(g x_{n(k)}, g y_{n(k)}\right)\right) \\
& +d\left(H\left(g y_{m(k)}, g x_{m(k)}\right), H\left(g y_{n(k)-1}, g x_{n(k)-1}\right)\right) \\
& +d\left(H\left(g y_{n(k)-1}, g x_{n(k)-1}\right), H\left(g y_{n(k)}, g x_{n(k)}\right)\right) \\
\leq & +\delta_{n(k)-1} .
\end{aligned}
$$

Letting $k \rightarrow \infty$ in (11) and using (8), we get

$$
\lim _{n \rightarrow \infty} D_{k}=\epsilon
$$

Again, for all $k \geq 0$, we have

$$
\begin{aligned}
D_{k} \leq & d\left(H\left(g x_{m(k)}, g y_{m(k)}\right), H\left(g x_{m(k)+1}, g y_{m(k)+1}\right)\right) \\
& +d\left(H\left(g x_{m(k)+1}, g y_{m(k)+1}\right), H\left(g x_{n(k)+1}, g y_{n(k)+1}\right)\right) \\
& +d\left(H\left(g x_{n(k)+1}, g y_{n(k)+1}\right), H\left(g x_{n(k)}, g y_{n(k)}\right)\right) \\
& +d\left(H\left(g y_{m(k)}, g x_{m(k)}\right), H\left(g y_{m(k)+1}, g x_{m(k)+1}\right)\right) \\
& +d\left(H\left(g y_{m(k)+1}, g x_{m(k)+1}\right), H\left(g y_{n(k)+1}, g x_{n(k)+1}\right)\right) \\
& +d\left(H\left(g y_{n(k)+1}, g x_{n(k)+1}\right), H\left(g y_{n(k)}, g x_{n(k)}\right)\right) \\
\leq & \delta_{m(k)}+\delta_{n(k)}+d\left(H\left(g x_{m(k)+1}, g y_{m(k)+1}\right), H\left(g x_{n(k)+1}, g y_{n(k)+1}\right)\right) \\
& +d\left(H\left(g y_{m(k)+1}, g x_{m(k)+1}\right), H\left(g y_{n(k)+1}, g x_{n(k)+1}\right)\right) .
\end{aligned}
$$

From (3) and $n(k)>m(k)$, we have

$$
\begin{aligned}
& \left(H\left(g x_{m(k)}, g y_{m(k)}\right), H\left(g y_{m(k)}, g x_{m(k)}\right),\right. \\
& \left.\quad H\left(g x_{m(k)+1}, g y_{m(k)+1}\right), H\left(g y_{m(k)+1}, g x_{m(k)+1}\right)\right) \in M
\end{aligned}
$$

and

$$
\begin{aligned}
& \left(H\left(g x_{m(k)+1}, g y_{m(k)+1}\right), H\left(g y_{m(k)+1}, g x_{m(k)+1}\right),\right. \\
& \left.\quad H\left(g x_{m(k)+2}, g y_{m(k)+2}\right), H\left(g y_{m(k)+2}, g x_{m(k)+2}\right)\right) \in M .
\end{aligned}
$$

Using $M$ has the transitive property, we get

$$
\begin{aligned}
& \left(H\left(g x_{m(k)}, g y_{m(k)}\right), H\left(g y_{m(k)}, g x_{m(k)}\right),\right. \\
& \left.\quad H\left(g x_{m(k)+2}, g y_{m(k)+2}\right), H\left(g y_{m(k)+2}, g x_{m(k)+2}\right)\right) \in M .
\end{aligned}
$$


Continuing this process, we have

$$
\begin{aligned}
& \left(H\left(g x_{m(k)}, g y_{m(k)}\right), H\left(g y_{m(k)}, g x_{m(k)}\right),\right. \\
& \left.\quad H\left(g x_{n(k)}, g y_{n(k)}\right), H\left(g y_{n(k)}, g x_{n(k)}\right)\right) \in M .
\end{aligned}
$$

From (1),(2) and (14), we have

$$
\begin{aligned}
d( & \left.H\left(g x_{m(k)+1}, g y_{m(k)+1}\right), H\left(g y_{n(k)+1}, g x_{n(k)+1}\right)\right) \\
& +d\left(H\left(g x_{m(k)+1}, g y_{m(k)+1}\right), H\left(g y_{n(k)+1}, g x_{n(k)+1}\right)\right) \\
= & d\left(F\left(x_{m(k)}, y_{m(k)}\right), F\left(x_{n(k)}, y_{n(k)}\right)\right) \\
& +d\left(F\left(y_{m(k)}, x_{m(k)}\right), F\left(y_{n(k)}, x_{n(k)}\right)\right) \\
\leq & \varphi\left(d\left(H\left(g x_{m(k)}, g y_{m(k)}\right), H\left(g x_{n(k)}, g y_{n(k)}\right)\right)\right. \\
& \left.+d\left(H\left(g y_{m(k)}, g x_{m(k)}\right), H\left(g y_{n(k)}, g x_{n(k)}\right)\right)\right) \\
= & \varphi\left(D_{k}\right),
\end{aligned}
$$

which, by (13), yields

$$
D_{k} \leq \delta_{m(k)}+\delta_{n(k)}+\varphi\left(D_{k}\right)
$$

Letting $k \rightarrow \infty$ in the above inequality and using (8) and (12), we get

$$
\epsilon=\lim _{k \rightarrow \infty} D_{k} \leq \lim _{k \rightarrow \infty}\left(\delta_{m(k)}+\delta_{n(k)}+\varphi\left(D_{k}\right)\right)=\lim _{D_{k} \rightarrow \epsilon^{+}} \varphi\left(D_{k}\right)<\epsilon,
$$

which is a contradiction. Hence, $\left\{H\left(g x_{n}, g y_{n}\right)\right\}_{n=1}^{\infty}$ and $\left\{H\left(g y_{n}, g x_{n}\right)\right\}_{n=1}^{\infty}$ are Cauchy sequences in $(X, d)$. Since $(X, d)$ is complete and (2), there exist $x, y \in X$ such that

$$
\begin{aligned}
& \lim _{n \rightarrow \infty} H\left(g x_{n}, g y_{n}\right)=\lim _{n \rightarrow \infty} F\left(x_{n}, y_{n}\right)=x \quad \text { and } \\
& \lim _{n \rightarrow \infty} H\left(g y_{n}, g x_{n}\right)=\lim _{n \rightarrow \infty} F\left(y_{n}, x_{n}\right)=y .
\end{aligned}
$$

Since the pair $\{F, H\}$ satisfies the generalized compatibility, from (17) we have

$$
\begin{aligned}
& \lim _{n \rightarrow \infty} d\left(F\left(H\left(g x_{n}, g y_{n}\right), H\left(g y_{n}, g x_{n}\right)\right), H\left(g F\left(x_{n}, y_{n}\right), g F\left(y_{n}, x_{n}\right)\right)\right)=0 \quad \text { and } \\
& \lim _{n \rightarrow \infty} d\left(F\left(H\left(g y_{n}, g x_{n}\right), H\left(g x_{n}, g y_{n}\right)\right), H\left(g F\left(y_{n}, x_{n}\right), g F\left(x_{n}, y_{n}\right)\right)\right)=0 .
\end{aligned}
$$

Since $F$ is continuous, for all $n \geq 0$, by the triangle inequality, we have

$$
\begin{aligned}
& d\left(H(g x, g y), F\left(H\left(g x_{n}, g y_{n}\right), H\left(g y_{n}, g x_{n}\right)\right)\right) \\
& \quad \leq d\left(H(g x, g y), H\left(g F\left(x_{n}, y_{n}\right), g F\left(y_{n}, x_{n}\right)\right)\right) \\
& \quad+d\left(H\left(g F\left(x_{n}, y_{n}\right), g F\left(y_{n}, x_{n}\right)\right), F\left(H\left(g x_{n}, g y_{n}\right), H\left(g y_{n}, g x_{n}\right)\right)\right)
\end{aligned}
$$


and

$$
\begin{aligned}
& d\left(H(g y, g x), F\left(H\left(g y_{n}, g x_{n}\right), H\left(g x_{n}, g y_{n}\right)\right)\right) \\
& \leq d\left(H(g y, g x), H\left(g F\left(y_{n}, x_{n}\right), g F\left(x_{n}, y_{n}\right)\right)\right) \\
& \quad+d\left(H\left(g F\left(y_{n}, x_{n}\right), g F\left(x_{n}, y_{n}\right)\right), F\left(H\left(g y_{n}, g x_{n}\right), H\left(g x_{n}, g y_{n}\right)\right)\right) .
\end{aligned}
$$

Taking the limit as $n \rightarrow \infty$ in (19) and (20), using (17),(18), and the fact that $H, F$ and $g$ are continuous, we have

$$
H(g x, g y)=F(x, y) \text { and } H(g y, g x)=F(y, x) .
$$

Therefore, $(x, y)$ is a coupled $g$-coincidence point of $F$ and $H$.

In our next theorem, we drop the continuity of $F$.

Theorem 3.2 Let $(X, d)$ be a complete metric space and $M$ be a non-empty subset of $X^{4}$. Assume that $g: X \rightarrow X$ is continuous and $F, H: X \times X \rightarrow X$ are two generalized compatible mappings such that $H$ is continuous and for any $x, y \in X$, there exist $u, v \in X$ such that $F(x, y)=H(g u, g v)$ and $F(y, x)=H(g v, g u)$. Suppose that there exists $\varphi \in \Phi$ such that the following holds:

$$
\begin{aligned}
& d(F(x, y), F(u, v))+d(F(y, x), F(v, u)) \\
& \quad \leq \varphi(d(H(g x, g y), H(g u, g v))+d(H(g y, g x), H(g v, g u)))
\end{aligned}
$$

for all $x, y, u, v \in X$ with $(H(g x, g y), H(g y, g x), H(g u, g v), H(g v, g u)) \in M$.

Also suppose that $(g(X), d)$ is a complete metric space, $H(X \times X) \subseteq g(X)$ and any two sequences $\left\{x_{n}\right\}$ and $\left\{y_{n}\right\}$ with $\left(x_{n}, y_{n}, x_{n+1}, y_{n+1}\right) \in M$ and $\left\{H\left(x_{n}, y_{n}\right)\right\} \rightarrow H(x, y),\left\{H\left(y_{n}, x_{n}\right)\right\} \rightarrow$ $H(y, x)$ for all $n \geq 1$ implies

$$
\left(H\left(x_{n}, y_{n}\right), H\left(y_{n}, x_{n}\right), H(x, y), H(y, x)\right) \in M
$$

for all $n \geq 1$. If there exist $x_{0}, y_{0} \in X$ such that

$$
\left(H\left(g x_{0}, g y_{0}\right), H\left(g y_{0}, g x_{0}\right), F\left(x_{0}, y_{0}\right), F\left(y_{0}, x_{0}\right)\right) \in M
$$

and $M$ is $\left(H_{g}, F\right)$-closed, then there exists $(x, y) \in X \times X$ such that $H(g x, g y)=F(x, y)$ and $H(g y, g x)=F(y, x)$, that is, $F$ and $H$ have a coupled $g$-coincidence point.

Proof As in the proof of Theorem 3.1. Since $(g(X), d)$ is complete, there exist $x, y \in X$ such that $g x, g y \in g(X)$, and we have

$$
\begin{aligned}
& \lim _{n \rightarrow \infty} H\left(g x_{n}, g y_{n}\right)=\lim _{n \rightarrow \infty} F\left(x_{n}, y_{n}\right)=g x \quad \text { and } \\
& \lim _{n \rightarrow \infty} H\left(g y_{n}, g x_{n}\right)=\lim _{n \rightarrow \infty} F\left(y_{n}, x_{n}\right)=g y .
\end{aligned}
$$


Since the pair $\{F, H\}$ satisfies the generalized compatibility, $H$ is continuous and by (3), we have

$$
\begin{aligned}
\lim _{n \rightarrow \infty} H\left(H\left(g x_{n}, g y_{n}\right), H\left(g y_{n}, g x_{n}\right)\right) & =H(g x, g y) \\
& =\lim _{n \rightarrow \infty} H\left(F\left(x_{n}, y_{n}\right), F\left(y_{n}, x_{n}\right)\right) \\
& =\lim _{n \rightarrow \infty} F\left(H\left(g x_{n}, g y_{n}\right), H\left(g y_{n}, g x_{n}\right)\right)
\end{aligned}
$$

and

$$
\begin{aligned}
\lim _{n \rightarrow \infty} H\left(H\left(g y_{n}, g x_{n}\right), H\left(g x_{n}, g y_{n}\right)\right) & =H(g y, g x) \\
& =\lim _{n \rightarrow \infty} H\left(F\left(y_{n}, x_{n}\right), F\left(x_{n}, y_{n}\right)\right) \\
& =\lim _{n \rightarrow \infty} F\left(H\left(g y_{n}, g x_{n}\right), H\left(g x_{n}, g y_{n}\right)\right) .
\end{aligned}
$$

From (3), (23), (24), by assumption, for all $n \geq 1$, we have

$$
\begin{aligned}
& \left(H\left(H\left(g x_{n}, g y_{n}\right), H\left(g y_{n}, g x_{n}\right)\right), H\left(H\left(g y_{n}, g x_{n}\right), H\left(g x_{n}, g y_{n}\right)\right),\right. \\
& H(g x, g y), H(g y, g x)) \in M .
\end{aligned}
$$

Then, by (1), (2), (25), and the triangle inequality, we have

$$
\begin{aligned}
& d(H(g x, g y), F(x, y))+d(H(g y, g x), F(y, x)) \\
& \leq d\left(H(g x, g y), F\left(H\left(g x_{n}, g y_{n}\right), H\left(g y_{n}, g x_{n}\right)\right)\right) \\
& \quad+d\left(F\left(H\left(g x_{n}, g y_{n}\right), H\left(g y_{n}, g x_{n}\right)\right), F(x, y)\right) \\
& \quad+d\left(H(g y, g x), F\left(H\left(g y_{n}, g x_{n}\right), H\left(g x_{n}, g y_{n}\right)\right)\right) \\
& \quad+d\left(F\left(H\left(g y_{n}, g x_{n}\right), H\left(g x_{n}, g y_{n}\right)\right), F(y, x)\right) \\
& \leq \varphi\left(d\left(H\left(H\left(g x_{n}, g y_{n}\right), H\left(g y_{n}, g x_{n}\right)\right), H(g x, g y)\right)\right. \\
&\left.+d\left(H\left(H\left(g y_{n}, g x_{n}\right), H\left(g x_{n}, g y_{n}\right)\right), H(g y, g x)\right)\right) \\
&+d\left(H(g x, g y), F\left(H\left(g x_{n}, g y_{n}\right), H\left(g y_{n}, g x_{n}\right)\right)\right) \\
&+d\left(H(g y, g x), F\left(H\left(g y_{n}, g x_{n}\right), H\left(g x_{n}, g y_{n}\right)\right)\right) .
\end{aligned}
$$

Letting now $n \rightarrow \infty$ in the above inequality and using the property of $\varphi$ that $\lim _{r \rightarrow 0^{+}} \varphi(r)=$ 0 , we have

$$
d(H(g x, g y), F(x, y))+d(H(g y, g x), F(y, x))=0,
$$

which implies that $H(g x, g y)=F(x, y)$ and $H(g y, g x)=F(y, x)$.

Next, we give an example to validate Theorem 3.1. 
Example 3.3 Let $X=[0,1], d(x, y)=|x-y|$ and $F, H: X \times X \rightarrow X$ be defined by

$$
F(x, y)=\frac{x^{2}+y^{2}}{16} \text { and } H(x, y)=x+y .
$$

Let $g: X \rightarrow X$ be defined by $g x=\frac{x}{2}$. Clearly, $H$ does not satisfy the mixed monotone property. Now, we prove that for any $x, y \in X$, there exist $u, v \in X$ such that $F(x, y)=H(g u, g v)$ and $F(y, x)=H(g v, g u)$. It is easy to see that there exist $u=\frac{x^{2}}{8}, v=\frac{y^{2}}{8} \in X$ such that

$$
F(x, y)=H\left(\frac{x^{2}}{16}, \frac{y^{2}}{16}\right)=H(g u, g v), \quad F(y, x)=H\left(\frac{y^{2}}{16}, \frac{x^{2}}{16}\right)=H(g v, g u) .
$$

Now, we prove that the pair $\{F, H\}$ satisfies the generalized compatibility hypothesis. Let $\left\{x_{n}\right\}_{n=1}^{\infty}$ and $\left\{y_{n}\right\}_{n=1}^{\infty}$ be two sequences in $X$ such that

$$
\begin{aligned}
& t_{1}=\lim _{n \rightarrow \infty} F\left(x_{n}, y_{n}\right)=\lim _{n \rightarrow \infty} H\left(g x_{n}, g y_{n}\right) \quad \text { and } \\
& t_{2}=\lim _{n \rightarrow \infty} F\left(y_{n}, x_{n}\right)=\lim _{n \rightarrow \infty} H\left(g y_{n}, g x_{n}\right) .
\end{aligned}
$$

Then we must have $t_{1}=0=t_{2}$, and it is easy to prove that

$$
\left\{\begin{array}{l}
\lim _{n \rightarrow \infty} d\left(F\left(H\left(x_{n}, y_{n}\right), H\left(y_{n}, x_{n}\right)\right), H\left(g F\left(x_{n}, y_{n}\right), g F\left(y_{n}, x_{n}\right)\right)\right)=0 \\
\lim _{n \rightarrow \infty} d\left(F\left(H\left(y_{n}, x_{n}\right), H\left(x_{n}, y_{n}\right)\right), H\left(g F\left(y_{n}, x_{n}\right), g F\left(x_{n}, y_{n}\right)\right)\right)=0 .
\end{array}\right.
$$

Now, for all $x, y, u, v \in X$ with $(H(g x, g y), H(g y, g x), H(g u, g v), H(g v, g u)) \in M=X^{4}$, and let $\varphi:[0,+\infty) \rightarrow[0,+\infty)$ be a function defined by $\varphi(t)=\frac{t}{4}$, then we have

$$
\begin{aligned}
d( & F(x, y), F(u, v))+d(F(y, x), F(v, u)) \\
& =\left|\frac{x^{2}+y^{2}}{16}-\frac{u^{2}+v^{2}}{16}\right|+\left|\frac{y^{2}+x^{2}}{16}-\frac{v^{2}+u^{2}}{16}\right| \\
& =2\left|\frac{\left(x^{2}-u^{2}\right)+\left(y^{2}-v^{2}\right)}{16}\right| \\
& =2\left|\frac{(x-u)(x+u)}{16}+\frac{(y-v)(y+v)}{16}\right| \\
& \leq \frac{1}{4}|(x+y)-(u+v)| \\
& =\varphi(|(x+y)-(u+v)|) \\
& =\varphi\left(\left|\frac{(x+y)}{2}-\frac{(u+v)}{2}\right|+\left|\frac{(y+x)}{2}-\frac{(v+u)}{2}\right|\right) \\
& =\varphi(d(H(g x, g y), H(g u, g v))+d(H(g y, g x), H(g v, g u))) .
\end{aligned}
$$

Therefore, condition (1) is satisfied. Thus, all the requirements of Theorem 3.1 are satisfied and $(0,0)$ is a coupled $g$-coincidence point of $F$ and $H$. 
Example 3.4 Let $X=[0,1], d(x, y)=|x-y|$ and $F, H: X \times X \rightarrow X$ be defined by

$$
F(x, y)= \begin{cases}\frac{x^{2}-y^{2}}{8} & \text { if } x \geq y \\ 0 & \text { if } x<y\end{cases}
$$

and

$$
H(x, y)= \begin{cases}x+y & \text { if } x \geq y \\ 0 & \text { if } x<y\end{cases}
$$

Let $g: X \rightarrow X$ by $g x=\frac{x}{2}$. Clearly, $H$ does not satisfy the mixed monotone property and if $x>y, u=v \neq 0$, consider

$$
\begin{aligned}
& H(g x, g y) \leq H(g u, g v) \Rightarrow \frac{x+y}{2} \leq \frac{u+v}{2} \\
& \quad \text { but } F(x, y)=\frac{x^{2}-y^{2}}{8}=\frac{(x-y)(x+y)}{8}>0=F(u, v) .
\end{aligned}
$$

Then $F$ is not $H_{g}$-increasing.

Now, we prove that for any $x, y \in X$, there exist $u, v \in X$ such that $F(x, y)=H(g u, g v)$ and $F(y, x)=H(g v, g u)$. It is easy to see the following cases.

Case 1: If $x=y$, then we have $F(y, x)=F(x, y)=0=H(g 0, g 0)=H(0,0)$.

Case 2: If $x>y$, then $(x-y) x>(x-y) y$, and we have

$$
F(x, y)=\frac{x^{2}-y^{2}}{8}=\frac{(x-y) x+(x-y) y}{8}=H\left(g \frac{(x-y) x}{4}, g \frac{(x-y) y}{4}\right)
$$

and

$$
F(y, x)=0=H\left(g \frac{(x-y) y}{4}, g \frac{(x-y) x}{4}\right)
$$

Case 3: If $y>x$, then $(y-x) y>(y-x) x$, and we have

$$
F(y, x)=\frac{y^{2}-x^{2}}{8}=\frac{(y-x) y+(y-x) x}{8}=H\left(g \frac{(y-x) y}{4}, g \frac{(y-x) x}{4}\right)
$$

and

$$
F(x, y)=0=H\left(g \frac{(y-x) x}{4}, g \frac{(y-x) y}{4}\right)
$$

Now, we prove that the pair $\{F, G\}$ satisfies the generalized compatibility hypothesis. Let $\left\{x_{n}\right\}_{n=1}^{\infty}$ and $\left\{y_{n}\right\}_{n=1}^{\infty}$ be two sequences in $X$ such that

$$
\begin{aligned}
& t_{1}=\lim _{n \rightarrow \infty} F\left(x_{n}, y_{n}\right)=\lim _{n \rightarrow \infty} G\left(g x_{n}, g y_{n}\right) \quad \text { and } \\
& t_{2}=\lim _{n \rightarrow \infty} F\left(y_{n}, x_{n}\right)=\lim _{n \rightarrow \infty} G\left(g y_{n}, g x_{n}\right) .
\end{aligned}
$$


Then we must have $t_{1}=0=t_{2}$, and it is easy to prove that

$$
\left\{\begin{array}{l}
\lim _{n \rightarrow \infty} d\left(F\left(H\left(x_{n}, y_{n}\right), H\left(y_{n}, x_{n}\right)\right), H\left(g F\left(x_{n}, y_{n}\right), g F\left(y_{n}, x_{n}\right)\right)\right)=0 \\
\lim _{n \rightarrow \infty} d\left(F\left(H\left(y_{n}, x_{n}\right), H\left(x_{n}, y_{n}\right)\right), H\left(g F\left(y_{n}, x_{n}\right), g F\left(x_{n}, y_{n}\right)\right)\right)=0 .
\end{array}\right.
$$

Now, for all $x, y, u, v \in X$ with $(H(g x, g y), H(g y, g x), H(g u, g v), H(g v, g u)) \in M=X^{4}$, and let $\varphi:[0,+\infty) \rightarrow[0,+\infty)$ be a function defined by $\varphi(t)=\frac{t}{4}$, then we have

$$
\begin{aligned}
d( & F(x, y), F(u, v))+d(F(y, x), F(v, u)) \\
& =\left|\frac{x^{2}-y^{2}}{8}-\frac{u^{2}-v^{2}}{8}\right|+\left|\frac{y^{2}-x^{2}}{8}-\frac{v^{2}-u^{2}}{8}\right| \\
& =2\left|\frac{x^{2}-y^{2}}{8}-\frac{u^{2}-v^{2}}{8}\right| \\
& =2\left|\frac{(x-y)(x+y)}{8}-\frac{(u-v)(u+v)}{8}\right| \\
& \leq \frac{1}{4}|(x+y)-(u+v)| \\
& =\varphi(|(x+y)-(u+v)|) \\
& =\varphi\left(\left|\frac{(x+y)}{2}-\frac{(u+v)}{2}\right|+\left|\frac{(y+x)}{2}-\frac{(v+u)}{2}\right|\right) \\
& =\varphi(d(H(g x, g y), H(g u, g v))+d(H(g y, g x), H(g v, g u))) .
\end{aligned}
$$

Therefore, condition (1) is satisfied. Thus, all the requirements of Theorem 3.1 are satisfied and $(0,0)$ is a coupled $g$-coincidence point of $F$ and $H$.

Next, we show the uniqueness of the coupled coincidence point and the coupled fixed point of $F$ and $H$.

Theorem 3.5 In addition to the hypotheses of Theorem 3.1, suppose that for every $(x, y),(z, t) \in X \times X$, there exists $(u, v) \in X \times X$ such that

$$
\begin{aligned}
& (H(g x, g y), H(g y, g x), H(g u, g v), H(g v, g u)) \in M \quad \text { and } \\
& (H(g z, g t), H(g t, g z), H(g u, g v), H(g v, g u)) \in M .
\end{aligned}
$$

Then F and G have a unique coupled g-coincidence point.

Proof From Theorem 3.1, we know that $F$ and $H$ have a coupled $g$-coincidence point. Suppose that $(x, y),(z, t)$ are coupled $g$-coincidence points of $F$ and $H$, that is,

$$
\begin{array}{ll}
F(x, y)=H(g x, g y), \quad F(y, x)=H(g y, g x) \quad \text { and } \\
F(z, t)=H(g z, g t), \quad F(t, z)=H(g t, g z) .
\end{array}
$$


Now, we show that $H(g x, g y)=H(g z, g t)$ and $H(g y, g x)=H(g t, g z)$. By the hypothesis, there exists $(u, v) \in X \times X$ such that

$$
\begin{aligned}
& (H(g x, g y), H(g y, g x), H(g u, g v), H(g v, g u)) \in M \quad \text { and } \\
& (H(g z, g t), H(g t, g z), H(g u, g v), H(g v, g u)) \in M .
\end{aligned}
$$

We put $g u_{0}=g u$ and $g v_{0}=g v$ and define two sequences $\left\{H\left(g u_{n}, g v_{n}\right)\right\}_{n=1}^{\infty}$ and $\left\{H\left(g v_{n}\right.\right.$, $\left.\left.g u_{n}\right)\right\}_{n=1}^{\infty}$ as follows:

$$
F\left(u_{n}, v_{n}\right)=H\left(g u_{n+1}, g v_{n+1}\right) \quad \text { and } \quad F\left(v_{n}, u_{n}\right)=H\left(g v_{n+1}, g u_{n+1}\right)
$$

for all $n \geq 0$.

Since $M$ is $\left(H_{g}, F\right)$-closed and $(H(g x, g y), H(g y, g x), H(g u, g \nu), H(g \nu, g u)) \in M$, we have

$$
\begin{aligned}
& (H(g x, g y), H(g y, g x), H(g u, g v), H(g v, g u)) \\
& \quad=\left(H(g x, g y), H(g y, g x), H\left(g u_{0}, g v_{0}\right), H\left(g v_{0}, g u_{0}\right)\right) \in M \\
& \Rightarrow \quad\left(F(x, y), F(y, x), F\left(u_{0}, v_{0}\right), F\left(v_{0}, u_{0}\right)\right) \\
& \quad=\left(H(g x, g y), H(g y, g x), H\left(g u_{1}, g v_{1}\right), H\left(g v_{1}, g u_{1}\right)\right) \in M .
\end{aligned}
$$

From $\left(H(g x, g y), H(g y, g x), H\left(g u_{1}, g v_{1}\right), H\left(g v_{1}, g u_{1}\right)\right) \in M$, if we use again the property of $\left(H_{g}, F\right)$-closed, then

$$
\begin{aligned}
& \left(H(g x, g y), H(g y, g x), H\left(g u_{1}, g v_{1}\right), H\left(g v_{1}, g u_{1}\right)\right) \in M \\
& \Rightarrow \quad\left(F(x, y), F(y, x), F\left(u_{1}, v_{1}\right), F\left(v_{1}, u_{1}\right)\right) \\
& \quad=\left(H(g x, g y), H(g y, g x), H\left(g u_{2}, g v_{2}\right), H\left(g v_{2}, g u_{2}\right)\right) \in M .
\end{aligned}
$$

By repeating this process, we get

$$
\left(H(g x, g y), H(g y, g x), H\left(g u_{n}, g v_{n}\right), H\left(g v_{n}, g u_{n}\right)\right) \in M \quad \text { for all } n \geq 0 .
$$

Using (1), (26) and (27), we have

$$
\begin{aligned}
& d\left(H(g x, g y), H\left(g u_{n+1}, g v_{n+1}\right)\right)+d\left(H(g y, g x), H\left(g v_{n+1}, g u_{n+1}\right)\right) \\
& \quad=d\left(F(x, y), F\left(u_{n}, v_{n}\right)\right)+d\left(F(y, x), F\left(v_{n}, u_{n}\right)\right) \\
& \quad \leq \varphi\left(d\left(H(g x, g y), H\left(g u_{n}, g v_{n}\right)\right)+d\left(H(g y, g x), H\left(g v_{n}, g u_{n}\right)\right)\right) \quad \text { for all } n .
\end{aligned}
$$

Using the property that $\varphi(t)<t$ and repeating this process, we get

$$
\begin{aligned}
& d\left(H(g x, g y), H\left(g u_{n+1}, g v_{n+1}\right)\right)+d\left(H(g y, g x), H\left(g v_{n+1}, g u_{n+1}\right)\right) \\
& \quad \leq \varphi^{n}\left(d\left(H(g x, g y), H\left(g u_{1}, g v_{1}\right)\right)+d\left(H(g y, g x), H\left(g v_{1}, g u_{1}\right)\right)\right) \quad \text { for all } n .
\end{aligned}
$$


From $\varphi(t)<t$ and $\lim _{r \rightarrow t^{+}} \varphi(r)<t$, it follows that $\lim _{n \rightarrow \infty} \varphi^{n}(t)=0$ for each $t>0$. Therefore, from (29) we have

$$
\lim _{n \rightarrow \infty}\left(d\left(H(g x, g y), H\left(g u_{n+1}, g v_{n+1}\right)\right)+d\left(H(g y, g x), H\left(g v_{n+1}, g u_{n+1}\right)\right)\right)=0 .
$$

This implies that

$$
\begin{aligned}
& \lim _{n \rightarrow \infty} d\left(H(g x, g y), H\left(g u_{n+1}, g v_{n+1}\right)\right)=0 \quad \text { and } \\
& \lim _{n \rightarrow \infty} d\left(H(g y, g x), H\left(g v_{n+1}, g u_{n+1}\right)\right)=0 .
\end{aligned}
$$

Similarly, we show that

$$
\begin{aligned}
& \lim _{n \rightarrow \infty} d\left(H(g z, g t), H\left(g u_{n+1}, g v_{n+1}\right)\right)=0 \quad \text { and } \\
& \lim _{n \rightarrow \infty} d\left(H(g t, g z), H\left(g v_{n+1}, g u_{n+1}\right)\right)=0 .
\end{aligned}
$$

From (31) and (32), we have

$$
H(g x, g y)=H(g z, g t) \quad \text { and } \quad H(g y, g x)=H(g t, g z) .
$$

Next, we give some application of our results to coupled coincidence point theorems in partially metric spaces with $F$ is $H_{g}$-increasing with respect to $\preceq$ and $H$ has the mixed monotone property.

Corollary 3.6 Let $(X, \preceq)$ be a partially ordered set and $M$ be a non-empty subset of $X^{4}$, and let $d$ be a metric on $X$ such that $(X, d)$ is a complete metric space. Assume that $g: X \rightarrow X$ is continuous and $F, H: X \times X \rightarrow X$ are two generalized compatible mappings such that $F$ is $H_{g}$-increasing with respect to $\preceq, H$ is continuous and has the mixed monotone property. Suppose that for any $x, y \in X$, there exist $u, v \in X$ such that $F(x, y)=H(g u, g v)$ and $F(y, x)=$ $H(g v, g u)$. Suppose that there exists $\varphi \in \Phi$ such that the following holds:

$$
\begin{aligned}
& d(F(x, y), F(u, v))+d(F(y, x), F(v, u)) \\
& \quad \leq \varphi(d(H(g x, g y), H(g u, g v))+d(H(g y, g x), H(g v, g u)))
\end{aligned}
$$

for all $x, y, u, v \in X$ with $H(g x, g y) \preceq H(g u, g v)$ and $H(g y, g x) \succeq H(g v, g u)$.

Also suppose that $F$ is continuous. If there exist $x_{0}, y_{0} \in X$ such that

$$
H\left(g x_{0}, g y_{0}\right) \preceq F\left(x_{0}, y_{0}\right) \quad \text { and } \quad H\left(g y_{0}, g x_{0}\right) \succeq F\left(y_{0}, x_{0}\right)
$$

and $M$ is $\left(H_{g}, F\right)$-closed, then there exists $(x, y) \in X \times X$ such that $H(g x, g y)=F(x, y)$ and $H(g y, g x)=F(y, x)$, that is, $F$ and $H$ have a coupled $g$-coincidence point.

Proof We define the subset $M \subseteq X^{4}$ by

$$
M=\left\{(x, y, u, v) \in X^{4}: x \preceq u \text { and } y \succeq v\right\} .
$$


From Example 2.21, $M$ is an $\left(H_{g}, F\right)$-closed set which satisfies the transitive property. For all $x, y, u, v \in X$ with $(H(g x, g y) \preceq H(g u, g v)$ and $H(g y, g x) \succeq H(g v, g u))$, we have $(H(g x, g y), H(g y, g x), H(g u, g v), H(g v, g u)) \in M$. By (1),we get

$$
\begin{aligned}
& d(F(x, y), F(u, v))+d(F(y, x), F(v, u)) \\
& \quad \leq \varphi(d(H(g x, g y), H(g u, g v))+d(H(g y, g x), H(g v, g u))) .
\end{aligned}
$$

Since $\left(x_{0}, y_{0}\right) \in X \times X$ with

$$
H\left(g x_{0}, g y_{0}\right) \preceq F\left(x_{0}, y_{0}\right) \quad \text { and } \quad H\left(g y_{0}, g x_{0}\right) \succeq F\left(y_{0}, x_{0}\right) \text {, }
$$

we have

$$
\left(H\left(g x_{0}, g y_{0}\right), H\left(g y_{0}, g x_{0}\right), F\left(x_{0}, y_{0}\right), F\left(y_{0}, x_{0}\right)\right) \in M \text {. }
$$

For the assumption holds, $F$ is continuous. By the assumption of Theorem 3.1, we have $H(g x, g y)=F(x, y)$ and $H(g y, g x)=F(y, x)$.

Corollary 3.7 Let $(X, \preceq)$ be a partially ordered set and $M$ be a non-empty subset of $X^{4}$, and let $d$ be a metric on $X$ such that $(X, d)$ is a complete metric space. Assume that $g: X \rightarrow X$ is continuous and $F, H: X \times X \rightarrow X$ are two generalized compatible mappings such that $F$ is $H_{g}$-increasing with respect to $\preceq, H$ is continuous and has the mixed monotone property. Suppose that for any $x, y \in X$, there exist $u, v \in X$ such that $F(x, y)=H(g u, g v)$ and $F(y, x)=$ $H(g v, g u)$. Suppose that there exists $\varphi \in \Phi$ such that the following holds:

$$
\begin{aligned}
& d(F(x, y), F(u, v))+d(F(y, x), F(v, u)) \\
& \quad \leq \varphi(d(H(g x, g y), H(g u, g v))+d(H(g y, g x), H(g v, g u)))
\end{aligned}
$$

for all $x, y, u, v \in X$ with $H(g x, g y) \preceq H(g u, g v)$ and $H(g y, g x) \succeq H(g v, g u)$.

Also suppose that $(g(X), d)$ is a complete metric space and $X$ has the following properties: for any two sequences $\left\{x_{n}\right\}$ and $\left\{y_{n}\right\}$,

(i) if a non-decreasing sequence $\left\{x_{n}\right\} \rightarrow x$, then $x_{n} \preceq x$ for all $n$,

(ii) if a non-increasing sequence $\left\{y_{n}\right\} \rightarrow y$, then $y \preceq y_{n}$ for all $n$.

If there exist $x_{0}, y_{0} \in X$ such that

$$
H\left(g x_{0}, g y_{0}\right) \preceq F\left(x_{0}, y_{0}\right) \quad \text { and } \quad H\left(g y_{0}, g x_{0}\right) \succeq F\left(y_{0}, x_{0}\right)
$$

and $M$ is $\left(H_{g}, F\right)$-closed, then there exists $(x, y) \in X \times X$ such that $H(g x, g y)=F(x, y)$ and $H(g y, g x)=F(y, x)$, that is, $F$ and $H$ have a coupled $g$-coincidence point.

Proof We define the subset $M \subseteq X^{4}$ by

$$
M=\left\{(x, y, u, v) \in X^{4}: x \preceq u \text { and } y \succeq v\right\} .
$$

From Example 2.21, $M$ is an $\left(H_{g}, F\right)$-closed set which satisfies the transitive property. For all $x, y, u, v \in X$ with $H(g x, g y) \preceq H(g u, g v)$ and $H(g y, g x) \succeq H(g v, g u)$, we have 
$(H(g x, g y), H(g y, g x), H(g u, g v), H(g v, g u)) \in M$. Let $\left(x_{0}, y_{0}\right) \in X \times X$ with

$$
H\left(g x_{0}, g y_{0}\right) \preceq F\left(x_{0}, y_{0}\right) \quad \text { and } \quad H\left(g y_{0}, g x_{0}\right) \succeq F\left(y_{0}, x_{0}\right)
$$

Using (2) and $F$ is $H_{g}$-increasing with respect to $\preceq$, we have

$$
H\left(g x_{n}, g y_{n}\right) \preceq H\left(g x_{n+1}, g y_{n+1}\right) \quad \text { and } \quad H\left(g y_{n}, g x_{n}\right) \succeq H\left(g y_{n+1}, g x_{n+1}\right) \quad \text { for all } n \text {. }
$$

Therefore, $\left(H\left(g x_{n}, g y_{n}\right), H\left(g y_{n}, g x_{n}\right), H\left(g x_{n+1}, g y_{n+1}\right), H\left(g y_{n+1}, g x_{n+1}\right)\right) \in M$.

From $(g(X), d)$ is complete, as in Theorem 3.1, we have two Cauchy sequences $\left\{H\left(g x_{n}\right.\right.$, $\left.\left.g y_{n}\right)\right\}_{n=1}^{\infty}$ and $\left\{H\left(g y_{n}, g x_{n}\right)\right\}_{n=1}^{\infty}$ such that $\left\{H\left(g x_{n}, g y_{n}\right)\right\}_{n=1}^{\infty}$ is a non-decreasing sequence in $X$ with $H\left(g x_{n}, g y_{n}\right) \rightarrow g x$ and $\left\{H\left(g y_{n}, g x_{n}\right)\right\}_{n=1}^{\infty}$ is a non-increasing sequence in $X$ with $H\left(g y_{n}, g x_{n}\right) \rightarrow g y$. Using assumption, we have

$$
H\left(g x_{n}, g y_{n}\right) \preceq g x \quad \text { and } H\left(g y_{n}, g x_{n}\right) \succeq g y \quad \text { for all } n
$$

Since $H$ has the mixed monotone property, we have

$$
\begin{aligned}
& H\left(H\left(g x_{n}, g y_{n}\right), H\left(g y_{n}, g x_{n}\right)\right) \preceq H(g x, g y), \\
& H\left(H\left(g y_{n}, g x_{n}\right), H\left(g x_{n}, g y_{n}\right)\right) \succeq H(g y, g x) .
\end{aligned}
$$

Therefore, we have

$$
\begin{aligned}
& \left(H\left(H\left(g x_{n}, g y_{n}\right), H\left(g y_{n}, g x_{n}\right)\right), H\left(H\left(g y_{n}, g x_{n}\right), H\left(g x_{n}, g y_{n}\right)\right),\right. \\
& H(g x, g y), H(g y, g x)) \in M
\end{aligned}
$$

for all $n \geq 1$. Now, since all the hypotheses of Theorem 3.2 hold, then $F$ and $H$ have a coupled $g$-coincidence point. The proof is completed.

Corollary 3.8 In addition to the hypotheses of Corollary 3.6, suppose that for every $(x, y),(z, t) \in X \times X$, there exists $(u, v) \in X \times X$ such that $(g u, g v)$ is comparable to ( $g x, g y)$ and $(g z, g t)$. Then $F$ and $H$ have a unique coupled $g$-coincidence point.

Proof We define the subset $M \subseteq X^{4}$ by

$$
M=\left\{(x, y, u, v) \in X^{4}: x \preceq u \text { and } y \succeq v\right\} .
$$

From Example 2.21, $M$ is an $\left(H_{g}, F\right)$-closed set which satisfies the transitive property. Thus, the proof of the existence of a coupled coincidence point is straightforward by following the same lines as in the proof of Corollary 3.6.

Next, we show the uniqueness of a coupled $g$-coincidence point of $F$ and $H$.

Since for all $(x, y),(z, t) \in X \times X$, there exists $(u, v) \in X \times X$ such that

$$
H(g x, g y) \preceq H(g u, g v), \quad H(g y, g x) \succeq H(g v, g u),
$$


and

$$
H(g z, g t) \preceq H(g u, g v), \quad H(g t, g z) \succeq H(g v, g u),
$$

we can conclude that

$$
\begin{aligned}
& (H(g x, g y), H(g y, g x), H(g u, g v), H(g v, g u)) \in M \quad \text { and } \\
& (H(g z, g t), H(g t, g z), H(g u, g v), H(g v, g u)) \in M .
\end{aligned}
$$

Therefore, since all the hypotheses of Theorem 3.5 hold, $F$ and $H$ have a unique $g$-coupled coincidence point. The proof is completed.

\section{Competing interests}

The authors declare that they have no competing interests.

Authors' contributions

The authors read and approved the final manuscript.

\section{Acknowledgements}

This research was supported by Chiang Mai University and the authors would like to express sincere appreciation to Prof. Suthep Suantai for very helpful suggestions and many kind comments.

Received: 10 June 2014 Accepted: 26 August 2014 Published: 26 Sep 2014

\section{References}

1. Ran, $A$, Reurings, $M$ : A fixed point theorem in partially ordered sets and some applications to matrix equations. Proc. Am. Math. Soc. 132, 1435-1443 (2004)

2. Nieto, JJ, Rodriguez-Lopez, R: Contractive mapping theorems in partially ordered sets and applications to ordinary differential equation. Order 22, 223-239 (2005)

3. Nieto, JJ, Rodriquez-Lopez, R: Existence and uniqueness of fixed point in partially ordered sets and applications to ordinary differential equation. Acta Math. Sin. Engl. Ser. 23(12), 2205-2212 (2007)

4. Agarwal, R, El-Gebeily, MA, O'Regan, D: Generalized contractions in partially ordered metric spaces. Appl. Anal. 87, 1-8 (2008)

5. Guo, D, Lakshmikantham, V: Coupled fixed points of nonlinear operators with applications. Nonlinear Anal. 11 , 623-632 (1987)

6. Gnana Bhaskar, T, Lakshmikantham, V: Fixed point theorems in partially ordered metric spaces and applications. Nonlinear Anal. TMA 65, 1379-1393 (2006)

7. Lakshmikantham, V, Ćirić, L: Coupled fixed point theorems for nonlinear contractions in partially ordered metric spaces. Nonlinear Anal. TMA 70, 4341-4349 (2009)

8. Abbas, M, Sintunavarat, W, Kumam, P: Coupled fixed point of generalized contractive mappings on partially ordered G-metric spaces. Fixed Point Theory Appl. 2012, 31 (2012)

9. Amini-Harandi, A: Coupled and tripled fixed point theory in partially ordered metric spaces with application to initial value problem. Math. Comput. Model. 57(910), 2343-2348 (2013)

10. Aydi, H, Damjanović, B, Samet, B, Shatanawi, W: Coupled fixed point theorems for nonlinear contractions in partially ordered G-metric spaces. Math. Comput. Model. 54, 2443-2450 (2011)

11. Aydi, $\mathrm{H}$, Postolache, $\mathrm{M}$, Shatanawi, W: Coupled fixed point results for $(\psi, \varphi)$-weakly contractive mappings in ordered G-metric spaces. Comput. Math. Appl. 63(1), 298-309 (2012)

12. Aydi, H, Karapinar, E, Shatanawi, W: Tripled fixed point results in generalized metric spaces. J. Appl. Math. 2012, Article ID 314279 (2012)

13. Aydi, H, Karapinar, E, Shatanawi, W: Tripled common fixed point results for generalized contractions in ordered generalized metric spaces. Fixed Point Theory Appl. 2012, 101 (2012)

14. Batra, R, Vashistha, S: Coupled coincidence point theorems for nonlinear contractions under $(F, g)$-invariant set in cone metric spaces. J. Nonlinear Sci. Appl. 6, 86-96 (2013)

15. Berinde, $\mathrm{V}$ : Generalized coupled fixed point theorems for mixed monotone mappings in partially ordered metric spaces. Nonlinear Anal. 74, 7347-7355 (2011)

16. Berinde, V: Coupled coincidence point theorems for mixed monotone nonlinear operators. Comput. Math. Appl. 64 1770-1777 (2012)

17. Berinde, $\mathrm{V}$ : Coupled fixed point theorems for $\varphi$-contractive mixed monotone mappings in partially ordered metric spaces. Nonlinear Anal., Theory Methods Appl. 75(6), 3218-3228 (2012)

18. Berinde, V: Coupled coincidence point theorems for mixed monotone nonlinear operators. Comput. Math. Appl. 64(6), 1770-1777 (2012)

19. Berzig, M, Samet, B: An extension of coupled fixed point's concept in higher dimension and applications. Comput. Math. Appl. 63, 1319-1334 (2012) 
20. Ćirić, L, Olatinwo, MO, Gopal, D, Akinbo, G: Coupled fixed point theorems for mappings satisfying a contractive condition of rational type on a partially ordered metric space. Adv. Fixed Point Theory 2(1), 1-8 (2012)

21. Chandok, S, Sintunavarat, W, Kumam, P: Some coupled common fixed points for a pair of mappings in partially ordered G-metric spaces. Math. Sci. 7, 24 (2013). doi:10.1186/2251-7456-7-24

22. Charoensawan, $\mathrm{P}$, Klanarong, $\mathrm{C}$ : Coupled coincidence point theorems for $\varphi$-contractive under $(f, g)$-invariant set in complete metric space. Int. J. Math. Anal. 7(33-36), 1685-1701 (2013)

23. Cho, YJ, Rhoades, BE, Saadati, R, Samet, B, Shatanawi, W: Nonlinear coupled fixed point theorems in ordered generalized metric spaces with integral type. Fixed Point Theory Appl. 2012, 8 (2012)

24. Choudhury, BS, Maity, P: Coupled fixed point results in generalized metric spaces. Math. Comput. Model. 54(1-2), 73-79 (2011)

25. Choudhury, BS, Kundu, A: A coupled coincidence point result in partially ordered metric spaces for compatible mappings. Nonlinear Anal. 73, 2524-2531 (2010)

26. Choudhury, BS, Gopal, D, Das, P: Coupled coincidence point results in fuzzy metric spaces without completeness. Ann. Fuzzy Math. Inform. 6(1) (2013)

27. Ding, H-S, Li, L: Coupled fixed point theorems in partially ordered cone metric spaces. Filomat 25(2), 137-149 (2011)

28. Hussain, $\mathrm{N}$, Latif, $\mathrm{A}$, Shah, $\mathrm{MH}$ : Coupled and tripled coincidence point results without compatibility. Fixed Point Theory Appl. 2012, 77 (2012)

29. Karapinar, E, Luong, NV, Thuan, NX, Hai, TT: Coupled coincidence points for mixed monotone operators in partially ordered metric spaces. Arab. J. Math. 1, 329-339 (2012)

30. Karapinar, E: Coupled fixed point theorems for nonlinear contractions in cone metric spaces. Comput. Math. Appl. 59, 3656-3668 (2010)

31. Karapinar, E: Couple fixed point on cone metric spaces. Gazi Univ. J. Sci. 24, 51-58 (2011)

32. Karapinar, E, Kaymakcalan, B, Tas, K: On coupled fixed point theorems on partially ordered G-metric spaces. J. Inequal. Appl. 2012, 200 (2012)

33. Karapinar, E, Kumam, P, Erhan, I: Coupled fixed points on partially ordered G-metric spaces. Fixed Point Theory Appl. 2012, 174 (2012). doi:10.1186/1687-1812-2012-174

34. Karapinar, E, Roldan, A, Martinez-Moreno, J, Roldan, C: Meir-Keeler type multidimensional fixed point theorems in partially ordered metric spaces. Abstr. Appl. Anal. 2013, 406026 (2013)

35. Kaushik, P, Kumar, S, Kumam, P: Coupled coincidence point theorems for $\alpha$ - $\psi$-contractive type mappings in partially ordered metric spaces. Fixed Point Theory Appl. 2013, 325 (2013). doi:10.1186/1687-1812-2013-325

36. Luong, NV, Thuan, NX: Coupled fixed points in partially ordered metric spaces and application. Nonlinear Anal. 74 983-992 (2011)

37. Mursaleen, M, Mohiuddine, SA, Agawal, RP: Coupled fixed point theorems for $\alpha-\psi$-contractive type mappings in partially ordered metric spaces. Fixed Point Theory Appl. 2012, 228 (2012)

38. Mursaleen, M, Mohiuddine, SA, Agawal, RP: Corrigendum to Coupled fixed point theorems for $\alpha-\psi$-contractive type mappings in partially ordered metric spaces. Fixed Point Theory and Appl. 2013, 127 (2013)

39. Roldan, A, Martinez-Moreno, J, Roldan, C: Multidimensional fixed point theorems in partially ordered complete metric spaces. J. Math. Anal. Appl. 396(2), 536-545 (2012)

40. Roldan, A, Martinez-Moreno, J, Roldan, C, Karapinar, E: Multidimensional fixed point theorems in partially ordered complete partial metric spaces under $(\psi, \varphi)$-contractivity conditions. Abstr. Appl. Anal. 2013, 634371 (2013)

41. Roldan, A, Karapinar, E: Some multidimensional fixed point theorems on partially preordered $G^{*}$-metric spaces under $(\psi, \varphi)$-contractivity conditions. Fixed Point Theory Appl. 2013, 158 (2013)

42. Shatanawi, W: Coupled fixed point theorems in generalized metric spaces. Hacet. J. Math. Stat. 40(3), 441-447 (2011)

43. Shatanawi, W, Abbas, M, Nazir, T: Common coupled coincidence and coupled fixed point results in two generalized metric spaces. Fixed Point Theory Appl. 2011, 80 (2011)

44. Sintunavarat, W, Kumam, P, Cho, YJ: Coupled fixed point theorems for nonlinear contractions without mixed monotone property. Fixed Point Theory Appl. 2012, 170 (2012)

45. Sintunavarat, W, Radenović, S, Golubović, Z, Kuman, P: Coupled fixed point theorems for F-invariant set. Appl. Math. Inf. Sci. 7(1), 247-255 (2013)

46. Sintunavarat, W, Kumam, P: Coupled coincidence and coupled common fixed point theorems in partially ordered metric spaces. Thai J. Math. 10(3), 551-563 (2012)

47. Hussain, N, Abbas, M, Azam, A, Ahmad, J: Coupled coincidence point results for a generalized compatible pair with applications. Fixed Point Theory Appl. 2014, 62 (2014). doi:10.1186/1687-1812-2014-62

48. Kutbi, MA, Rolda'n, A, Sintunavarat, W, Marti'nez-Moreno, J, Rolda'n, C: F-Closed sets and coupled fixed point theorems without the mixed monotone property. Fixed Point Theory Appl. 2013, 330 (2013). doi:10.1186/1687-1812-2013-330

49. Samet, B, Vetro, C: Coupled fixed point F-invariant set and fixed point of $N$-order. Ann. Funct. Anal. 1, 46-56 (2010)

50. Sintunavarat, W, Cho, YJ, Kumam, P: Coupled fixed point theorems for weak contraction mappings under $F$-invariant set. Abstr. Appl. Anal. 2012 (2012)

51. Sintunavarat, W, Petrusel, A, Kumam, P: Common coupled fixed point theorems for $w^{*}$-compatible mappings without mixed monotone property. Rend. Circ. Mat. Palermo 61(3), 361-383 (2012)

52. Doric, D, Kadelburgb, Z, Radenovic'c, S: Coupled fixed point results for mappings without mixed monotone property. Appl. Math. Lett. 25(11), 1803-1808 (2012)

53. Charoensawan, $P$, Thangthong, C: On coupled coincidence point theorems on partially ordered G-metric spaces without mixed g-monotone. J. Inequal. Appl. 2014, 150 (2014). doi:10.1186/1029-242X-2014-150

54. Charoensawan, P: Tripled coincidence point theorems for a $\phi$-contractive mapping in a complete metric space without the mixed $g$-monotone property. Fixed Point Theory Appl. 2013, 252 (2013)

55. Karapinar, E, Kumam, P, Sintunavarat, W: Coupled fixed point theorems in cone metric spaces with a c-distance and applications. Fixed Point Theory Appl. 2012, 194 (2012)

56. Karapinar, E, Roldan, A, Shahzad, N, Sintunavarat, W: Discussion of coupled and tripled coincidence point theorems for $\phi$-contractive mappings without the mixed $g$-monotone property. Fixed Point Theory Appl. 2014, 92 (2014) 
10.1186/1687-1812-2014-201

Cite this article as: Na Nan and Charoensawan: Coupled g-coincidence point theorems for a generalized compatible pair in complete metric spaces. Fixed Point Theory and Applications 2014, 2014:201

Submit your manuscript to a SpringerOpen ${ }^{\circ}$ journal and benefit from:

- Convenient online submission

- Rigorous peer review

- Immediate publication on acceptance

Open access: articles freely available online

- High visibility within the field

- Retaining the copyright to your article

Submit your next manuscript at $\boldsymbol{s p r i n g e r o p e n . c o m ~}$ 